\title{
A Study on Oxygen Consumption in a Freshwater Fish Cyprinus carpio Exposed to Lethal and Sublethal Concentrations of Cypermethrin (25\% Ec)
}

\author{
P. Neelima, N. Gopala Rao, G. Srinivasa Rao and J. Chandra Sekhara Rao* \\ Department of Zoology and Aquaculture, Acharya Nagarjuna University, \\ Nagarjuna Nagar-522510, Guntur, A.P., India \\ *Corresponding author
}

\begin{abstract}
A B S T R A C T
Keywords

Cypermethrin

toxicity,

Oxygen

consumption,

Cyprinus

carpio.

\section{Article Info}

Accepted:

15 March 2016

Available Online:

10 April 2016

Short-term definitive test by static renewal bioassay method was conducted to determine the acute toxicity $\left(\mathrm{LC}_{50}\right)$ of commercial grade synthetic insecticide, cypermethrin (25\% EC) and its impact on oxygen consumption in a freshwater edible fish, Cyprinus carpio. Fingerlings were exposed to lethal $(3.31 \mu \mathrm{g} / \mathrm{L})$ and sublethal $(0.331 \mu \mathrm{g} / \mathrm{L})$ concentrations of cypermethrin for 96h. In sub-lethal concentration, experimental fish Cyprinus carpio showed an increased tendency in oxygen consumption during the initial time of exposures i.e. 2 to 4 hours and a gradual decrease during the subsequent study period. Fish showed gradual decrease in oxygen consumption from the starting period of exposure to till the end of the experiment in lethal concentration. Alterations in oxygen consumption may be due to respiratory distress as a consequence of impaired oxidative metabolism.
\end{abstract}

\section{Introduction}

Any alteration in fish physiology indicates the deterioration of water quality parameters, since fish are one of the biological indicators of water quality. The recent development of biomarkers based on the study of the response of organisms to toxic chemicals has provided essential tools for the implementation of environment contamination monitoring programmes (Korami et al., 2000). Toxicants in the environment mainly enter into fish by means of their respiratory system. Respiratory activity of a fish is often the first physiological response to be affected by the presence of toxic pollutants in the aquatic media.
These responses were found to be less sensitive, but could be used successfully in environmental monitoring. A change in respiration rate is one of the common physiological responses to toxicants and is easily detectable through changes in oxygen consumption rate, which is frequently used to evaluate the changes in metabolism under environmental deterioration.

Fish bioassay experiments are indices to determine the acute toxicity and possible effect on oxygen consumption due to the pollutant stress (Subrahmanyam, 2004). Although many biological early warning 
systems monitor abnormal opercular movement as an indicator of respiratory stress, a more direct measurement of stress in this sense necessitates the quantification of oxygen consumed by the fish (Dube and Hosette, 2010). Studies on oxygen consumption form a suitable tool in the assessment of stress due to toxicants on the aquatic organisms and give an index of energy expenditure mechanisms for environmental variations (Franklin et al., 2010; Logaswamy and Remia, 2009; Francesco et al., 2008; Sornaraj et al., 2005). Total oxygen consumption of fish reflects its basal metabolic status and is one of the indicators of the general health or/and well being of the fish. It may also be useful to assess the physiological state of an organism, helps in evaluating the susceptibility or resistance potentiality and also useful to correlate the behaviour of the animal, which ultimately serve as predictors of functional disruptions of population. Fish being animal are heterotrophic. It is often used as a bioindicator of pollution associated stress in biological early warning systems. Hence, differential oxygen consumption can be used as a bioindicator of pollution associated stress in biological early warning systems.

Oxygen $\left(\mathrm{O}_{2}\right)$ in its molecular state is essential for many metabolic processes that are vital to aerobic life. Like all aerobic organisms, fish are susceptible to the effects of reactive oxygen and have inherent and effective of different biotic and abiotic factors on antioxidant defenses in fish (Martinez-Alvarez et al., 2005). Determination of oxygen consumption by the fish is useful for assessment of lethal effects and is one of the important indicators which reflect physiological state of animal. In aquatic body toxicants present above the normal level i.e., at lethal concentrations bring about mortality of fish and also increase the rate of oxygen consumption in survived fish (Tilak et al., 2007).

A variation in respiration rate is an indicator of stress and is frequently used to evaluate the changes in metabolism under environmental deterioration (Chebbi and David, 2010). Pesticides are indicated to cause respiratory distress or even failure by affecting respiratory centres of the brain or the tissue involved in breathing. Numerous studies such as Cirrhinus mrigala (Mushigeri and David, 2003), Labeo rohita (Patil and David, 2008), Oreochromis mossambicus (Logaswamy and Remia, 2009), Ctenopharyngodon idella (Tilak and Swarna Kumari, 2009); Oreochromis niloticus (Barbieri and Ferriera, 2010) and Cyprinus carpio (Singh et al., 2010) reported either increase or decrease their respiration rate in response to variety of pesticides.

Like most fish, carps are oxygen regulators, meaning that they maintain their oxygen consumption at a constant level along a gradient of environmental oxygen concentrations, until a critical oxygen concentration is reached, below which oxygen consumption begins to fall. Under conditions of stress, this critical oxygen is likely to increase, reflecting the decreased capacity of the fish to cope with environmental perturbations. Analysis of oxygen consumption can be used as a biodetectory system to evaluate the basic damage inflicted on the animal which could either increase or decrease the oxygen uptake. Hence, the present study was undertaken to evaluate the toxicity of lethal and sublethal concentrations of cypermethrin $25 \% \mathrm{EC}$ on oxygen consumption of the freshwater teleost fish Cyprinus carpio.

\section{Materials and Methods}

Experiment on the oxygen consumption of the fish Cyprinus carpio was carried out in a respiratory apparatus developed by Job (1955). The fish were brought from a local fish farm at Nandivelugu, Guntur District (Andhra Pradesh). They were acclimatized to the laboratory conditions in well aerated water for 10 days. The water used for fish acclimatization and experimentation was the same as used in the toxicity experiments 
(Table 3.1). During the experimental period, the fish were regularly fed, but the feeding was stopped for two days prior to the experiment. The fish measuring 6 to $8 \mathrm{~cm}$ in length and 6.5 to $7.5 \mathrm{gm}$ in weight were used in the experiment. All the precautions laid down by APHA (1998) are followed, for maintaining the fish. The fish were exposed to 96h $\mathrm{LC}_{50}$ lethal $(3.31 \mu \mathrm{g} / \mathrm{l})$, sublethal $\left(1 / 10^{\text {th }}\right.$ of 96h $\mathrm{LC}_{50}$ i.e., $\left.0.331 \mu \mathrm{g} / \mathrm{l}\right)$, concentrations of synthetic pyrethroid pesticide cypermethrin ( $25 \%$ EC). The samples for estimation were taken from the respiratory chamber, at alternate hours of intervals for 24 hours. The amount of dissolved oxygen consumption was calculated per gram body weight per hour.

\section{$\mathrm{O}_{2}$ consumed by fish / gram body weight / hour $=$}

$\alpha-\beta \times \mathrm{N}$ of hypo $\times 8 \times 1000$

Vol. of the sample x Correction factor $\mathrm{x}$ Wt. of the fish $\mathrm{x}$ Time interval for sample

$\alpha=$ hypo rundown before exposure

$\beta=$ hypo rundown after exposure

Student's t-test was employed to calculate the significance of the differences between control and experimental means. $P$ values of 0.05 or less were considered statistically significant (Fisher, 1950).

\section{Results and Discussion}

Comparative data on the whole animal oxygen consumption of control and experimental fish, calculated per gram body weight in lethal and sublethal concentrations of cypermethrin $25 \%$ EC formulation for Cyprinus carpio was given in table 1 . The results of the experiments and control values are graphically represented in Figure 1 by taking time on $\mathrm{X}$ axis and the amount of oxygen consumed per gram body weight on $\mathrm{Y}$ axis. A comparison was made between the controls and experimental fish under lethal and sub lethal concentrations of cypermethrin $25 \% \mathrm{EC}$ to the fish Cyprinus carpio for every $2 \mathrm{~h}$. In sub-lethal concentrations of cypermethrin $25 \%$ EC, it was observed that experimental fish Cyprinus carpio showed an increased tendency in oxygen consumption during the initial time of exposures i.e. 2 to 4 hours and a gradual decrease was observed during the subsequent study period. It was observed that, fish showed gradual decrease in oxygen consumption from the starting period of exposure to till the end of the experiment in lethal concentrations of cypermethrin $25 \%$ EC. The rate of oxygen consumption was gradually decreased in control fish also.

Cypermethrin induced Respiratory alterations were studied by Jipsa et al., 2014; Logaswamy and Remia, 2009; David et al., 2003 (Tilapia mossambica); Sree Veni and Veeraiah, 2014; Prashant et al., (2003) (Cirrhinus mrigala); Marigoudar et al., 2009a (Labeo rohita); (Tilapia mossambica); Joshi and Kulkarni, 2007 (Garra mullya); Shivakumar et al., 2006 (Cyprinus carpio). It is clearly evident from the present study that the cypermethrin affected oxygen consumption of Cyprinus carpio under both lethal and sublethal concentrations. The initial increase in oxygen uptake observed may be due to the stress caused by the toxicant cypermethrin on the fish making it active to combat the stress, thus incurring an increased requirement of energy. The increase in activity might be to boost up oxidative metabolism for an increased supply of energy to combat the toxic stress (David et al., 2003). This probably accounts for an elevation in oxygen consumption.

Subsequent decrease in oxygen consumption indicates either increased entry of cypermethrin molecules or its accumulation in the body as a function of time. The decrease in oxygen consumption in sub lethal concentrations of the cypermethrin appears to be mainly due to lowering down of energy requirements which can be considered as adaptive and even strategic (Tilak and Vardhan, 2002). In addition the fish might 
have overcome the pesticide toxicity by triggering the process of detoxification. In the present investigation, depletion of the oxygen consumption is due to the disorganization of the respiratory action caused by rupture in the respiratory epithelium of the gill tissue. Oxygen consumption decreases with the time of exposure to the toxicant is evidenced in the findings of Tilak and Swarnakumari (2009). Under toxic conditions, the oxygen supply becomes deficient and a number of poisons become more toxic increasing the amount of poison being exposed to the animal. The fish breathe more rapidly and the amplitude of respiratory movements will increase. It can be inferred from the results that, during sublethal exposure to toxicant, the fish may be adapting to augment the physiological adjustment for elimination of the chemical stress. These findings are in accordance with findings of various authors in which increased oxygen consumption was observed: Veeraiah (2002) in Labeo rohita exposed to cypermethrin, Shereena et al., (2009) in Tilapia mossambica exposed to dimethoate.

The presence of sub-lethal concentration of toxicants is inevitable. In such a case, the fish Cyprinus carpio was more sensitive to toxicant. The toxicant stress in oxygen consumption along with depletion in oxygen in aquacultures practices make them less fit and reduction in growth due to lack of proper metabolism. The data as per table 3.1, the fish was in more stress during first hour and later they are showing signs of recovery. That recovery is evident as the toxicant exposure is increased in time, during $24 \mathrm{~h}$ experiment. The fish are in more stress during first hour and later they showed signs of recovery. Throughout the experimental period the fish showed severe respiratory distress and rapid opercular movements leading to the higher amount of toxicant uptake, increased mucous secretion, higher ventilation volume, decrease in oxygen uptake efficiency, laboured breathing and engulfing of air through the mouth when exposed to cypermethrin $25 \%$ EC. That recovery is evident as the toxicant exposure is increased in time during 12 hours experiment.

Decrease can also be attributed to the induction of hypoxic conditions within the animal due to the intimate contact of the respiratory surface with toxic water resulting in the alteration of normal respiratory area of the animal. As aquatic organisms have their outer bodies and important organs such as gills almost entirely exposed to water, the effect of toxicants on the respiration is more pronounced. Pesticides enter into the fish mainly through gills and with the onset of symptoms of poisoning, the rate of oxygen consumption increases. Since, gills are the major respiratory organs; all metabolic pathways depend upon the efficiency of the gills for their energy supply in the fish. Damage to these vital organs causes a chain of destructive events, which ultimately lead to respiratory distress (Magare and Patil, 2000).

Changes in the gill architecture and increased mucus production under cypermethrin stress is consistent with the observed histological effects such as hyperplasia, necrosis and lamellar aneurysms in Cyprinus carpio exposed to sublethal concentrations of the toxicant, cypermethrin. Secretion of mucus over the gill curtails the diffusion of oxygen which may ultimately reduce the oxygen uptake by the animal. Since gill is the target organ for synthetic pyrethroid toxicity in fish, the toxicant will pass through the gills, and interfere in the gill movements which are directly proportional to the respiratory activity of the fish, primarily affecting the oxygen uptake.

If gills or membrane functions are destroyed due to xenobiotic chemicals or the membrane functions are disturbed by a change in permeability the oxygen uptake rate would rapidly decrease (Hartl et al., 2001). Further, the metabolic rate in relation to respiration of fish could be increased under chemical stress (Chebbi and David, 2010). The stressful behaviour of respiratory impairment due to the 
toxic effect of cypemethrin on the gills was similar with the report of Omitoyin et al., (2006) and Aguigwo (2002). According to Patil et al., (2003), the gill movement increased at the initial phase and gradually decreased towards the lethal phase. It is presumed that the toxicant directly or indirectly affects the respiration of fish. The rate of oxygen consumed by the affected fish was very low. Once the respiration of the fish is affected, in turns all the biological activities of the fish will also be reduced. The decrease in whole animal oxygen consumption might be due to the damage in the structural integrity of the cells of respiratory organs.

Since most fish breathe in the water in which they live, changes in the chemical properties in it may be reflected in the animal's ventilator activity, particularly if the environment factors affect respiratory gas exchange (Mushigeri, 2003). The fluctuated response in respiration may be attributed to respiratory distress as a consequence of the impairment of oxidative metabolism. Since the gills are the main respiratory organ, water continuously passes over them, and in this process, oxygen is consumed. Therefore, if toxicants appear in the water, then the gills will be affected first. Dharmalata and Namitha Joshi (2002) reported that the respiration is a vital phenomenon of the life and the rate of oxygen consumption in turn controls the metabolic activities and changes in respiratory rates have been used as the indicator of the stress in pollutant exposed organisms.

Fish in the sublethal concentration were found under stress, but that was not fatal (Murthy et al., 2013). In sub lethal medium, the respiration rate of fish decreased in the subsequent period of exposure which might be due to acclimatization of the fish in the chemical environment. The intimate contact of gills with toxicant may lead to defection of normal respiratory area that is damage of gill tissue which in turn may reduce the diffusion capacity of the gill leading the depression in oxygen uptake.
Aquatic animals have to pass large quantities of water over their respiratory surface and are subjected to relatively greater risk of exposure to the toxic substances (Shelke and Wani, 2005). Investigations of Anita Susan (2010); Shereena et al. (2009), Logaswamy and Remia (2009), Patil and David (2008), Vutukuru (2005), Shivakumar and David (2004), Rao et al. (2003) and David et al., (2003) revealed that the disturbance in oxidative metabolism leads alteration in completely animal oxygen consumption in different species of fish exposed to pesticides.

During experimentation the control fish demanded more oxygen in the early hours later got settled and maintained a constant uptake of oxygen, while the exposed fish demanded more oxygen in the initial hours and later showed a decrease in the oxygen demand. In the present study the initial elevation in the rate of oxygen consumption could be explained in terms of acceleration of oxidative metabolism during the initial hours of exposure, as a result of sudden response to the toxic stimulus of the pesticide. The alternative reasons for the elevation of oxygen consumption would be due to the internal action of Cypermethrin. After 24h, rate of oxygen consumption declines when compared to normal fish and with the onset of symptoms of poisoning, the rate decreased in the later periods of exposure, probably due to acclimatization to the chemical environment. This decline in oxygen consumption is in consonance with the diminished levels of oxidative enzymes after $48 \mathrm{~h}$ of cypermethrin exposure as observed earlier Shivakumar and David (2004). Since symptoms of pesticide toxicity normally involve respiratory distress, the decreased oxygen consumption of the cypermethrin exposed fish is probably due to the absorbance of more pesticide through the gills Logaswamy and Remia (2009).

As gills, the most important organs of respiration, are continuously exposed to water to absorb vital oxygen, they become the first target to come in contact with external 
toxicant environment. Therefore the gill, in general, showed marked pathological changes such as bulging in the tips of primary gill lamellae, club shaped secondary gill lamellae, fusion of secondary gill filaments, proliferation of interlamellar cells, separation of epithelial layer from the central sinus of the filament and dilation of primary gill lamellae. In aquatic media, over stimulation or depression of respiratory activity is one of the most important manifestations of toxicity of chemical pollutants. Steady and progressive decline in ventilatory pattern and decline in oxygen consumption are noticeable with few exceptions difficult to generalize (Veeraiah and Durga Prasad, 2001)

Jipsa et al., 2014 determined the effect of cypermethrin on oxygen in Tilapia mossambica and reported altered rate of oxygen consumption under sublethal concentration of cypermethrin at 24, 48, 72 and $96 \mathrm{~h}(0.446,0.094,0.194$ and $0.197 \mathrm{ml} / \mathrm{g} / \mathrm{h})$ compared to control $(0.462 \mathrm{ml} / \mathrm{g} / \mathrm{h})$. Sree Veni and Veeraiah (2014) studied toxicity of cypermethrin $(10 \% \quad$ EC) on oxygen consumption of Cirrhinus mrigala and reported increased respiratory activity, resulting in increased ventilation and increased uptake of the toxicant, due to stress.

Marigoudar et al., 2009 investigated cypermethrin induced respiratory alterations in Labeo rohita. Fish exposed to lethal concentration $(4 \mu \mathrm{g} / \mathrm{l})$ for $1,2,3$ and 4 days showed increased oxygen consumption on day $1(8.597 \%)$ to day $2(17.409 \%)$ and the increase was decreased $(1.289 \%)$ on day 4 . In sublethal $\left(1 / 5^{\text {th }}\right.$ of $96 \mathrm{~h} \mathrm{LC}_{50}$ i.e. $\left.0.57 \mu \mathrm{g} / \mathrm{l}\right)$ concentration for $1,5,10$ and 15 days, oxygen consumption increased on days 1, 5, 10 and 15 as compared to the control in the order of 1 $(20.580 \%)<5(39.44 \%)<10(102.57 \%)<15$ $(109.77 \%)$. They concluded that the alteration in oxygen consumption may be due to the respiratory distress as a consequence of impairment in oxidative metabolism due to stress. The present work coincides with the report of the same. Impact of sublethal concentrations of cypermethrin on respiratory activity of Tilapia mossambica was studied by Logaswamy and Remia (2009) for 24, 48, 72 and $96 \mathrm{~h}$ intervals. Rate of oxygen consumption was declined during all the exposure periods.

Table.1 The Amount of Oxygen Consumed in Mg/G Body Weight/Hr of Cyprinus Carpio Exposed to Lethal and Sublethal Concentration of Cypermethrin (25\% EC)

\begin{tabular}{|c|c|c|c|c|c|}
\hline $\begin{array}{c}\text { Hours } \\
\text { of Exposure }\end{array}$ & Control & Sublethal & $\begin{array}{c}\text { \% Variation } \\
\text { over Control }\end{array}$ & Lethal & $\begin{array}{c}\text { \% Variation } \\
\text { over Control }\end{array}$ \\
\hline 0 & $0.779 \pm 0.018$ & $0.763 \pm 0.012$ & 2.05 & $0.769 \pm 0.011$ & 1.28 \\
\hline 2 & $0.771 \pm 0.012$ & $1.179 \pm 0.006$ & 52.91 & $0.718 \pm 0.008$ & 6.87 \\
\hline 4 & $0.761 \pm 0.014$ & $1.261 \pm 0.012$ & 65.70 & $0.676 \pm 0.010$ & 11.16 \\
\hline 6 & $0.744 \pm 0.016$ & $0.731 \pm 0.014$ & 1.74 & $0.625 \pm 0.012$ & 15.99 \\
\hline 8 & $0.732 \pm 0.018$ & $0.686 \pm 0.011$ & 6.28 & $0.591 \pm 0.013$ & 19.26 \\
\hline 10 & $0.701 \pm 0.020$ & $0.622 \pm 0.012$ & 11.2 & $0.541 \pm 0.018$ & 22.82 \\
\hline 12 & $0.685 \pm 0.017$ & $0.578 \pm 0.014$ & 15.62 & $0.501 \pm 0.016$ & 26.86 \\
\hline 14 & $0.671 \pm 0.018$ & $0.502 \pm 0.016$ & 25.18 & $0.462 \pm 0.013$ & 31.14 \\
\hline 16 & $0.650 \pm 0.024$ & $0.436 \pm 0.021$ & 32.92 & $0.414 \pm 0.016$ & 36.30 \\
\hline 18 & $0.638 \pm 0.015$ & $0.393 \pm 0.019$ & 38.40 & $0.365 \pm 0.020$ & 42.78 \\
\hline 20 & $0.620 \pm 0.013$ & $0.364 \pm 0.018$ & 41.29 & $0.312 \pm 0.011$ & 49.67 \\
\hline 22 & $0.601 \pm 0.018$ & $0.343 \pm 0.021$ & 42.92 & $0.288 \pm 0.008$ & 52.07 \\
\hline 24 & $0.589 \pm 0.012$ & $0.323 \pm 0.017$ & 45.16 & $0.235 \pm 0.007$ & 60.10 \\
\hline
\end{tabular}

Values are the mean of five observations; Standard Deviation is indicated as $( \pm)$.

Value are significant at $p<0.05$ 
Figure.1 The Amount of Oxygen Consumed in mg/g/Body Weight/h/of the Fish Exposed to Sublethal and Lethal Concentrations of Cypermethrin (25\%EC)

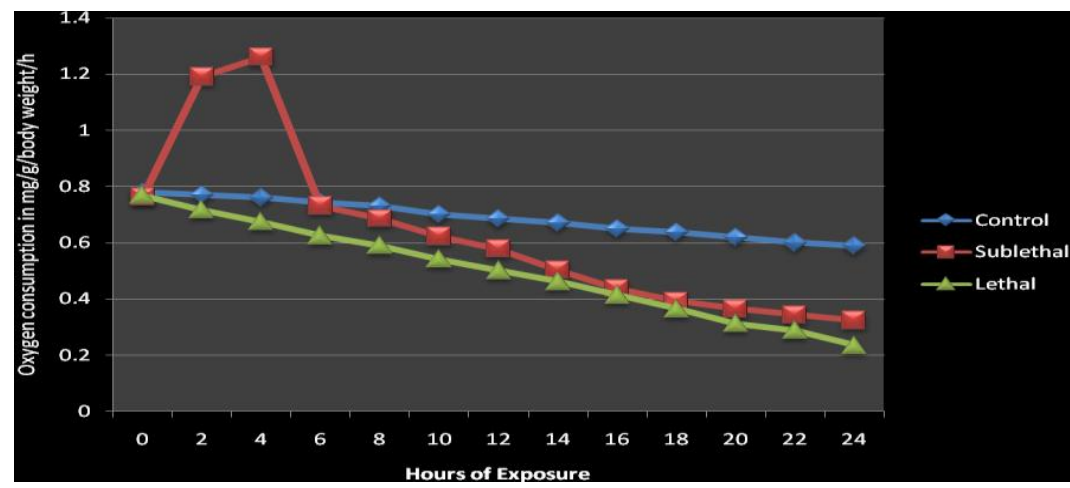

Joshi and Kulkarni (2007) studied the effect of cypermethrin and fenevelerate on oxygen consumption of the freshwater hill stream fish Garra mullya (Skyes) and reported the rate of oxygen consumption increased in the initial period of analysis in both lethal and sublethal concentrations started decreasing. Finally they concluded alteration in oxygen consumption increased and thereafter decreased which is a bioindicator for assessing the pesticide toxicity, which can be correlated with the present study. Shivakumar et al. (2006) observed increased opercular movements in Cyprinus carpio exposed to cypermethrin.

David et al., (2003) showed disturbances in oxidative metabolism in Tilapia mossambica under cypermethrin toxicity. Prashanth et al. (2003) studied effect of cypermethrin on toxicity and oxygen consumption in Cirrhinus mrigala and reported decreased level of oxygen consumption exposed to lethal concentration for 1, 2, 3 and 4 days and also in sublethal concentration of $1,7,14$ and 21 days. Decrement may be due to the respiratory distress as a consequence of the impaired oxidative metabolism.

In conclusion, the analysis of data from the present investigation demonstrated that cypermethrin is highly toxic and had a profound impact on respiration in Cyprinus carpio in both lethal and sublethal concentrations. Variation in the oxygen consumption in cypermethrin exposed fish was probably due to impaired oxidative metabolism and pesticide induced stress. The amount of oxygen consumption by the experimental fish reflects its total metabolic rate and hence the energy output. Changes in gill architecture under cypermethrin stress would alter the diffusing capacity of gill with consequent hypoxic or anoxic conditions, thus, respiration may become a problematic task for the fish. These results suggest that the altered rates of respiration in Cyprinus carpio may also serve as a rapid biological monitor to assess the impact of pesticides such as cypermethrin on other biotic communities in the water body.

\section{Acknowledgement}

Authors are thankful to the Head, Department of Zoology \& Aquaculture and the authorities of Acharya Nagarjuna University for the encouragement and support by providing necessary facilities. Corresponding author is thankful to Dr. G. Simhachalam, Assistant Professor, Department of Zoology for his valuable suggestions and for using his laboratory for the present study.

\section{References}

Aguigwo, J.N. 2002. The toxic effects of cymbush pesticide on growth and survival of African catfish, Clarias gariepinus (Burchell). Aquatic Science, 17: 81-84.

Anita Susan, T., Sobha, K., Tilak, K.S. 2010. A study on acute toxicity, oxygen consumption 
and behavioural changes in the three major carps, Labeo rohita (ham), Catla catla (ham) and Cirrhinus mrigala (ham) exposed to Fenvalerate. Bioresearch Bull., 1: 35-43.

APHA. 1998. American Public Health Association. In: Standard methods for the examination of water and waste water. APHA/AWWA/WPCF, Washington, DC.

Barbieri, E., Ferreira, L.A.A. 2010. Effects of the organophosphate pesticide Folidol 600® on the freshwater fish, Nile Tilapia (Oreochromis niloticus). Pesticide Biochem. Physiol., 99: 209-214.

Chebbi, S.G., David, M. 2010. Respiratory responses and behavioural anomalies of the carp Cyprinus carpio under quinalphos intoxication in sublethal doses. Sci. Asia, 36: $12-17$.

David, M., Shiva Kumar, H.B., Shiva Kumar, R., Mushigeri, S.B., Ganti, B.H. 2003. Toxicity evaluation of cypermethrin and its effect on oxygen consumption of the freshwater fish, Tilapia mossambica. Indian J. Environ. Toxicol., 13(2): 99-102.

Dharmalata, Joshi, N. 2002. Toxicity and Respiratory responses of Heteropneustesfossilis exposed to zinc chloride and fly ash leachate. Himalayan $J$. Environ. Zool., 16(1): 87-90.

Dube, B.N., Hosetti, B.B. 2010. Respiratory distress and Behavioural anomalies of Indian Major carp Labeo rohita (Hamilton) exposed to Sodium cyanide. Recent Res. Sci. Technol., 2(2): 42-48.

Fisher, R.A. 1950. Statistical Methods for research workers, $11^{\text {th }}$ edition, (Edinburgh UK: Oliver and Boyd Ltd.).

Francesco, P., Francesca, I., Umile, G.S., Giuseppe, C., Manuela, C., Nevio, P. 2008. Polymer in Agriculture: a Review. American J. Agri. Biol. Sci., 3: 299-314.

Franklin, R.K., Loo, H.S., Osumanu, H.A. 2010. Incorporation of Bentazone with Exserohilum rostratum for controlling Cyperus iria. American J. Agri. Biol. Sci., 5: 210-214.

Hartl, M.G.J., Hutchinson, S., Hawkins, L. 2001. Organotin and osmoregulation: quantifying the effects of environmental concentrations of sediment associated TBT and TPhT on the freshwater adapted European flounder, Platichthys flesus. J. Experimental Marine Biol. Ecol., 256: 267-278.

Jipsa. J.R., Kalavathi, R., Dhanya, P.Y.,
Logaswamy, S. 2014. Studies on the impact of a Cypermethrin insecticide on oxygen consumption and certain biochemical constituents of a fish Tilapia mossambica. Int. J. Fisheries and Aquatic Studies, 1(5): 93-97.

Job, S.V. 1955. The oxygen consumption of Salvelinas fontinalis Pubs. Out. Fisheries Res. Laboratory, 73: 1-39.

Joshi, P.P., Kulkarni, G.K. 2007. Change in the oxygen consumption of a freshwater fish Garra mulya (Sykes) exposed to cypermethrin and fenvalerate. Himalayan J. Environ. Zool., 21(1): 7-13.

Korami, D., Eric, H., Charles, G. 2000. Concentration effects of selected insecticides on brain acetylcholinesterases in the common carp (Cyprinus carpio L.). Ecotoxicol. Environmental Safety, 45: 95-105.

Logaswamy, S., Remia, K.M. 2009. Impact of cypermethrin and ekalux on respiratory and some biochemical activities of a freshwater fish, Tilapia mossambica. J. Curr. Biotica, 3(1): 65-73.

Magare, S.R., Patil, H.T. 2000. Effect of pesticides on oxygen consumption. Red blood cell count and metabolites of fish, Puntius ticto. Environ. Ecol., 18(4): 891-894.

Marigoudar, S.R., Ahmed, R.N., David, M. 2009. Cypermethrin induced respiratory and behavioural responses of the freshwater teleost, Labeo rohita (Hamilton). Veterinarski Arhiv, 79(6): 583-590.

Martínez-Álvarez, R.M., Morales, A.E., Sanz, A. 2005. Antioxidant defenses in fish: Biotic and abiotic factors. Reviews in Fish Biology and Fisheries, 15: 75-88.

Murthy, K.S., Kiran, B.R., Venkateshwarlu, M. 2013. A review on toxicity of pesticides in Fish. Int. J. Open Sci. Res., 1(1): 15-36.

Mushigeri, S.B. 2003. Effect of fenvalerate on the metabolism of Indian major carp, Cirrhinus mrigala. PhD. thesis, India, Karnataka, Dharwad: Karnatak University.

Mushigeri, S.B., David, M. 2003. Assessment of Fenvelerate toxicity on oxygen consumption and ammonia excretion in the freshwater fish, Cirrhinus mrigala. J. Ecotoxicol. Environ. Monitoring, 13: 191-195.

Omitoyin, B.O., Ajani, E.K., Adesina, B.T., Okuagu, C.N.F. 2006. Toxicity of lindane (Gamman Hexachloro-Cyclohexane) to Clarias gariepinus. International Digital Organization for Scientific Information, 1(1): 
$57-63$.

Patil, J.A., Patil, A., Govindwar, S.P. 2003. Biochemical effects of various pesticides on sprayers of grape gardens. Indian J. Clin. Biochem., 2: 16-22.

Patil, V.K., David, M. 2008. Behaviour and respiratory dysfunction as an index of malathion toxicity in the freshwater fish, Labeo rohita (Hamilton). Turkish J. Fisheries and Aquatic Sci., 8: 233-237.

Prashanth, M.S., David, M., Kuri, R.C. 2003. Effect of Cypermethrin on Toxicity and Oxygen Consumption in the Freshwater Fish, Cirrhinus mrigala. J. Ecotoxicol. Environ. Monitoring, 13: 271-277.

Rao, J.V., Rani, C.H.S., Kavitha, P., Rao, R.N., Madhavendra, S.S. 2003. Toxicity of chlorpyrifos to the fish, Oreochromis mossambicus.

Bull. Environ. Contamination and Toxicol., 70: 985-992.

Shelke, A.D., Wani, G.P. 2005. Respiratory Response of a Fresh Water Teleost Fish, Amblypharyngodon mola. J. Aquatic Biol., 20: 193-196.

Shereena, K.M., Logaswamy, S., Sunitha, P. 2009. Effect of an organophosphorous pesticides (Dimethoate) on oxygen consumption of the fish Tilapia mossambica. Recent Res. Sci. Technol., 1: 4-7.

Shivakumar, R., David, M. 2004. Toxicity of endosulfan to the freshwater fish, Cyprinus carpio. Indian J. Ecol., 31: 27-29.

Shivakumar, R., Mushigeri, S.B., David, M. 2006. Toxicity of Endosulfan, Cypermethrin and Fenvalerate to freshwater fish, Cyprinus carpio. J. Ecobiol., 19(4): 313-316.

Singh, K.S., Singh, S.K.S.,Yadav, R.P. 2010. Toxicological and biochemical alterations of cypermethrin (synthetic pyrethroid) against freshwater teleost Colisa fasciatus at different seasons. World J. Zool., 5(7): 25-32.

Somaraj, I.R., Ranjitsingh, A.J., Pushparaj, A., Ramathilagam, G. 2005. Pesticidal stress influenced respiratory alterations in the fresh water fish, Mystus vittatus. Indian $J$. Environ. Ecoplanning, 10: 803-806.

Sree Veni, S.M., Veeraiah, K. 2014. Effect of Cypermethrin (10\%EC) on Oxygen Consumption and Histopathology of Freshwater Fish Cirrhinus mrigala (Hamilton). IOSR J. Environ. Sci., Toxicol. Food Technol., 8(10): 12-20.

Subramanian, M.A. 2004. Toxicology, M J P Publishers, Chennai. p. 202.

Tilak, K.S., Swarnakumari, R. 2009. Acute toxicity of Nuvan, an organophosphate to freshwater fish, Ctenopharyngodon idellus and its effect on oxygen consumption. J. Environ. Biol., 30(6): 1031-1033.

Tilak, K.S., Vardhan, S.K. 2002. Effect of fenvalerate on oxygen consumption and haematological parameters in the fish, Channa punctatus (Bloch). J. Aquatic Biol., 17: 81-86.

Tilak, K.S., Veeraiah, K., Thathaji, P.B. 2007. Histopathological changes in the kidney of the fish Channa punctata exposed to sublethal concentration of Butachlor and Machete. $J$. Ecotoxicol. Environ. Monitoring, 17(2): 129134.

Veeraiah, K. 2002. Cypermethrin toxicity and its impact on histochemical and histological changes in the Indian major carp Labeo rohita (Hamilton). Ph.D. Thesis submitted to Nagarjuna University, Nagarjuna Nagar, Guntur, A.P. India.

Veeraiah, K., Durga Prasad, M.K. 2001. Studies on ventilatory patterns of fish under normal and stressed conditions using indigenously designed electronic recording instrument. Proceedings of the International Conference of ICIPACT.

Vutukuru, S.S. 2005. Acute Effects of Hexavalent Chromium on Survival, Oxygen Consumption, Haematological Parameters and Some Biochemical Profiles of the Indian Major Carp, Labeo rohita. Int. J. Environ. Res. Pub. Health, 2(3): 456-462.

\section{How to cite this article:}

Neelima, P., N. Gopala Rao, G. Srinivasa Rao and Chandra Sekhara Rao, J. 2016. A Study on Oxygen Consumption in a Freshwater Fish Cyprinus carpio Exposed to Lethal and Sublethal Concentrations of Cypermethrin (25\%Ec). Int.J.Curr.Microbiol.App.Sci.5(4): 338-346.

doi: http://dx.doi.org/10.20546/ijcmas.2016.504.040 